NBER WORKING PAPER SERIES

\title{
HIRING RISKY WORKERS
}

Edward P. Lazear

Working Paper 5334

\author{
NATIONAL BUREAU OF ECONOMIC RESEARCH \\ 1050 Massachusetts Avenue \\ Cambridge, MA 02138 \\ November 1995
}

This work was supported in part by the National Science Foundation. It was prepared for presentation at the K.I.E.R. conference on internal labor markets in Biwako, Japan held July, 1995. I gratefully acknowledge comments provided by Anat Admati, Paul Pfleiderer, John Roberts, Fiona Scott Morton, Robin Wells and Jeffrey Zwiebel and especially comments of my discussants, Hiroshi Osano and Toshiaki Tachibanaki. This paper is part of NBER's research program in Labor Studies. Any opinions expressed are those of the author and not those of the National Bureau of Economic Research.

( $) 1995$ by Edward P. Lazear. All rights reserved. Short sections of text, not to exceed two paragraphs, may be quoted without explicit permission provided that full credit, including () notice, is given to the source. 
NBER Working Paper 5334

November 1995

\title{
HIRING RISKY WORKERS
}

\begin{abstract}
It has long been recognized in finance and other literature that variance provides option value. The same point carries over to the labor market. Firms like variance in new employees because they can keep the good workers and terminate the bad ones. But market wages must adjust to make the marginal firm indifferent between high and low variance workers. The market equilibrium for new, risky workers is explored to determine how workers and firms line up on the various sides of the market. Firms in growing industries prefer young, high variance workers. Growing industries will be characterized by high turnover rates. In order for risky workers to provide option value, it is necessary that the initial employer have some advantage over other firms. Private information or mobility costs can provide that advantage. Also required is that the risk have a firm specific component. General variations in ability provide no option value to an initial hirer.
\end{abstract}

Edward P. Lazear

Graduate School of Business

Stanford University

Stanford, CA 94305-5015

and Hoover Institution and NBER 
Uncertainty presents a major challenge to employers who are formulating a hiring policy. Despite best efforts, worker quality is not known with certainty at the time of hire. Indeed, precise information on worker quality may never be available. Firms must make employment decisions under uncertainty. But uncertainty, generally regarded negatively, has a positive feature: If an employer cannot assess precisely a worker's productivity, there is a chance that the worker will turn out better than expected, instead of worse. Variance provides employers an option: Risky workers have value because a better-than-expected worker can be kept and a worse-than-expected worker can be terminated. This point raises a number of questions. Should a firm favor risky hires over safe ones? When should a firm invest to increase the information that it has about a job candidate? Consistent with the optimizing behavior of firms is the market equilibrium that results. What can be said about the nature of this equilibrium? How, for example, does the market value risk in new candidates? Are there predictable variations in compensation for "new" versus "used" candidates?

The questions are tackled in a model that describes the market for workers of uncertain quality as they compete for jobs against those whose quality is more precisely known. The main results are:

1. Risky workers are preferred to safe ones at a given wage. Because the risky worker has option value, a firm is willing to pay more to hire a worker with upside potential.

2. The wage premium that risky new workers command varies directly with the length of the remaining worklife and inversely with the time that it takes to determine the worker's productivity. Restrictions on firing workers can reduce the value of the risky worker relative 
to the safe one, but cannot reverse the preference for risky over safe.

3. As an extension, young workers are favored over old ones with the same expected value. Since less is known about young workers, they have more option value. A similar argument may provide a rationale for preferring male to female workers.

4. Still, information has value. Firms are willing to pay to learn about a worker's true productivity. This way, the firm can eliminate having to tolerate low productivity workers during a probation period in order to find the ones that it wants to retain.

5. Market equilibrium ensures that wages adjust to make the marginal firm indifferent between hiring the risky worker and the safe worker. New firms in growing industries prefer younger, riskier workers. Firms in declining industries prefer older, safer workers. As a result, Silicon Valley should have younger workers and higher turnover rates than the Rust Belt.

6. The initial employer must have some ex post advantage over other firms or the option value vanishes. Private information, which becomes available to the initial employer alone, or mobility costs of some kind are examples of the kind of advantage needed to produce option value.

A Model of the Hiring and Pay Decisions Under Uncertainty:

There are three primary issues that this section addresses. First, how do firms view variance among new employees? Second, given their view, how do wages adjust to bring about market equilibrium? Third, what do these factors imply about hiring policy? 
A general model is sufficient to provide some specific answers to these questions. ${ }^{1}$ Consider a competitive labor market with entering workers of two types. The safe type has certain output, $\Pi$, and the risky worker has general output $M$, which is a random variable, with mean $\bar{M}$. In addition, the risky worker has an unknown firm specific output, $\mathrm{S}_{\mathrm{i}}$, which gives the worker's specific output at firm i. ${ }^{2}$ Assume that $E(S)=0$ and that $S_{i}$ is independent of $S_{j}$, for all $i, j$, and of $M$. Thus, total output at firm $i$ is given by $M+S_{i}$.

The worker's worklife begins at time 0 and ends at time $T$. In addition, the worker's ability is learned by the firm that hires him at time $\tau, 0 \leq \tau \leq T$. Knowledge of a worker's ability is not public, but whether the firm has fired or retained him is. ${ }^{3}$ There is no requirement that information be asymmetric. In this model, the knowledge that the worker has on his ability is irrelevant.

Because output has a firm specific component to it, a worker fired by one firm may be hired by another, even at the same wage rate. Conversely, the wage that the initial firm is willing to pay to a retained worker is different from the wage that another firm would be willing to offer a retained worker.

It is clear that the worker with certain output will be paid ${ }^{M}$ per period of time, which is equal to his product. The pay for risky workers is somewhat less obvious. First,

\footnotetext{
'Some early work by Rothschild (1974) and Weitzman (1979) reveals the value of being able to choose a unknown over known payoff structures. Much of this relates to the statistical literature by Gittins and Jones (1974). Also, see Reinganum (1983).

2The safe worker could also have a firm specific component to output. But if it is known at the time of hire, it simply serves to sort workers to specific firms and places a lower bound on the wage that the worker must be paid.

'Waldman (1984) assumes that promotions and other job-related moves are observable by outsiders, but that ability is not. This model makes assumptions similar to his.
} 
since worker ability cannot be distinguished initially, the wage per period until time $\tau$ must be the same for all individuals. Denote this wage $W_{1}$ and call the period between 0 and $\tau$ "probation." At time $\tau$, worker ability becomes known. The firm will want to keep all workers whose output exceeds their wage. It will fire only those workers whose wage during the post probation period exceeds output. Thus, if the wage paid during the post probation period is denoted $W_{T}$, then the firm retains all workers for whom

$$
M+S_{1}>W_{T}
$$

where $S_{1}$ is defined as the firm-specific component at the firm that hires the rookie worker. Workers whose output falls below $\mathrm{W}_{\mathrm{T}}$ are denied the right to continue at wage $\mathrm{W}_{\mathrm{T}}$.

How is $W_{T}$ set? This is the wage that the firm must pay in order to stave off raids by other firms. The amount that another firm, say, firm $j$, would be willing to offer a worker who is retained by the initial firm is

(2) $\mathrm{W}_{\mathrm{T}}=\mathrm{E}\left(\mathrm{M}+\mathrm{S}_{\mathrm{j}} \mid \mathrm{M}+\mathrm{S}_{1}>\mathrm{W}_{\mathrm{T}}\right)$.

The r.h.s. is the expected output of a worker at firm $j$ who was retained by firm $i$. Because of specificity, the values are not the same at the two firms and this allows firm $i$ to pay retained workers a wage higher than firm $j$ would offer.

For there to exist an equilibrium, it is necessary that (2) have a solution. Any wage greater than $\mathrm{W}_{\mathrm{T}}$ will retain the desired workers, but the initial firm may not be able to

The mechanisms described here are similar to other layoff models, e.g., Lazear (1986), Greenwald (1986) and Gibbons and Katz (1991). 
commit credibly to paying wages above $\mathrm{W}_{\mathrm{T}}$. Because of the specificity of the information, the amount that firm $j$ will offer to those retained is $W_{T}$ (neither the actual value of $M+S_{j}$ nor the actual value of $\left.M+S_{1}\right)$.

It is shown first that a solution to (2) exists. If a solution exists, then there is a postprobation wage for retained workers that cannot be matched by other firms and that will induce retention only of those whose output exceeds that wage.

Rewrite (2) as

(3) $\quad E\left(M \mid M+S_{1}>W_{T}\right)-W_{T}=0$

because $E\left(S_{j}\right)=0$. Evaluate the l.h.s. of $(3)$ for $W_{T}=\min (M)$. Since

$E\left(M \mid M+S_{1}>\min (M)\right)>\min (M),{ }^{b}$

the 1.h.s. is positive for $\mathrm{W}_{\mathrm{T}}=\min (\mathrm{M})$.

Conversely, evaluate the l.h.s. of $(3)$ for $W_{T}=\max (M)$. Since

$E\left(M \mid M+S_{1}>\max (M)\right)<\max (M){ }^{6}$

the 1.h.s. is negative for $W_{T}=\max (M)$.

As long as the densities of $M$ and $S_{1}$ are continuous, the expectations are continuous.

This integrates over the range where $S_{1}<0$.

This integrates over the range where $S_{1}$ is positive. It is the specificity that guarantees that the conditional expectation of $M$ deviate from $\mathrm{W}_{\mathrm{T}}$. 


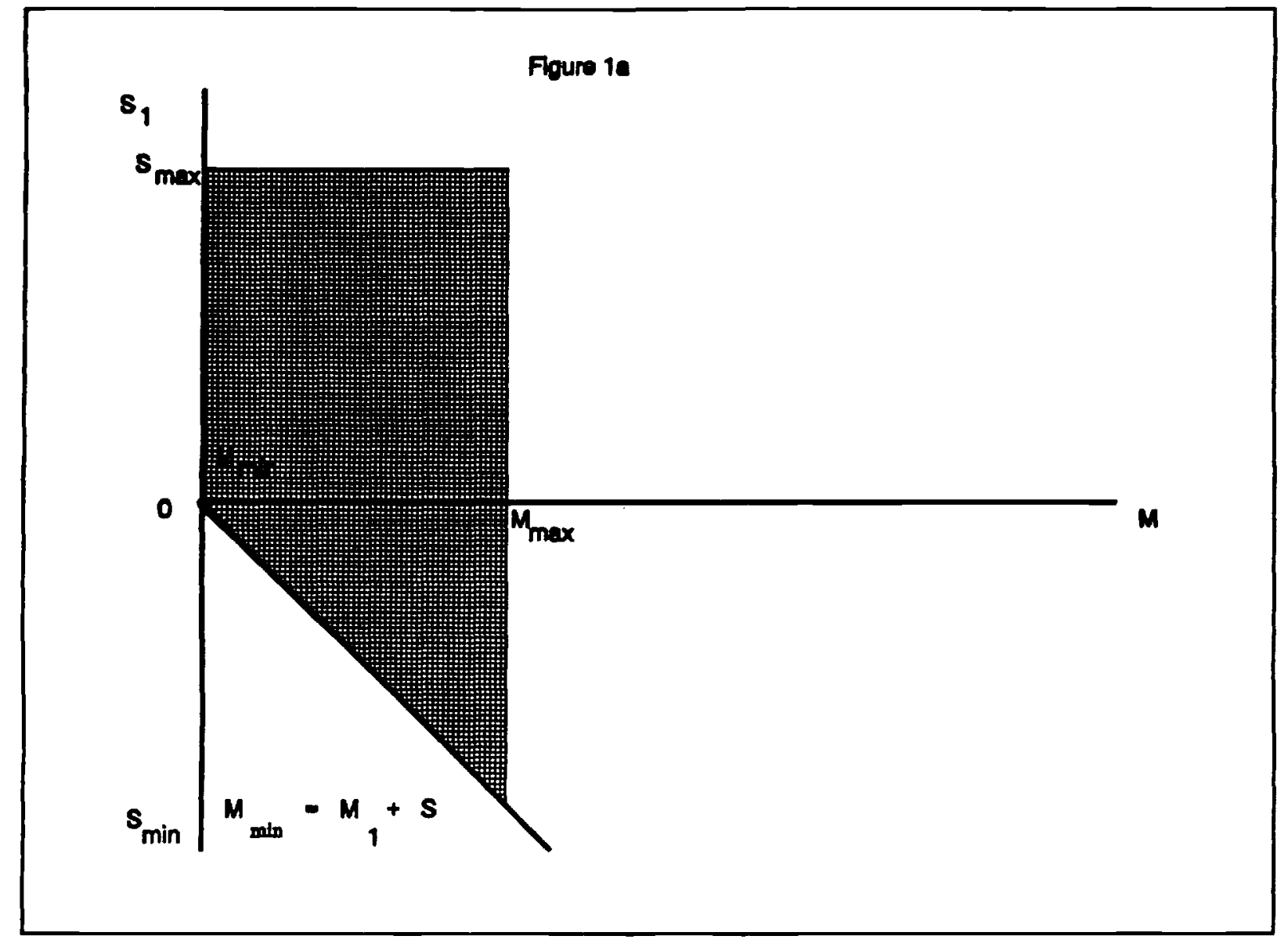

Since the l.h.s. goes from a positive value to a negative value, continuity guarantees that the l.h.s. must equal zero for some value of $W_{T}$, so a solution to (3) exists.

Figs. $1 \mathrm{a}$ and $1 \mathrm{~b}$ illustrate the situation. In fig. $1 \mathrm{a}, \mathrm{W}_{\mathrm{T}}$ is set equal to $\min (\mathrm{M})$. The area that satisfies $M+S_{1}>W_{T}$ is shaded. The expectation of $M$ in this area is always greater than $\min (M)$. Similarly, in fig. $1 \mathrm{~b}, \mathrm{~W}_{\mathrm{T}}$ is set equal to $\max (\mathrm{M})$. The area that satisfies $M+S_{1}$ $>W_{T}$ is shaded. The expectation of $M$ in this area is always less than max (M).

A market equilibrium wage, $W_{\mathrm{T}}$, exists such that outsiders offer retained workers $\mathrm{W}_{\mathrm{T}}$ and the initial firm keeps only workers whose value exceeds $W_{\mathrm{T}}$. Workers who are risky at the time of hire are sorted two categories after probation. One group is retained at wage $W_{T}$, which equals the expected alternative value of retained workers. The price that the initial 


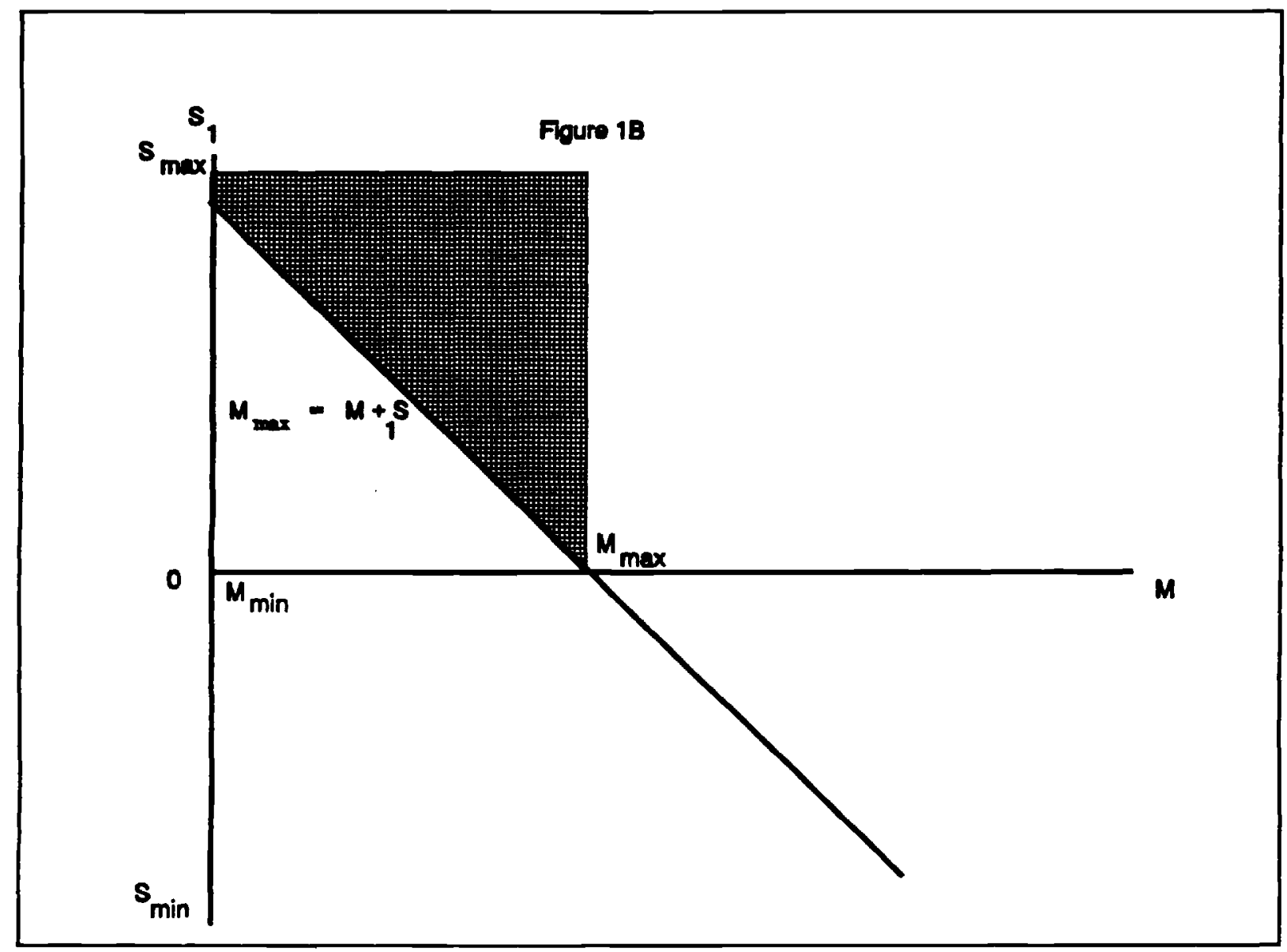

firm can commit to pay is $\mathrm{W}_{\mathrm{T}}$ because that is the maximum amount that an outsider will pay for retained workers. ${ }^{7}$ The other group of workers is terminated outright. They have output at the initial firm that falls short of $\mathrm{W}_{\mathrm{T}}$. Since outsiders would be willing to offer these workers $\mathrm{W}_{\mathrm{T}}$ were they retained, the initial firm will let them go.

It is now possible to state a few results. First,

${ }^{7}$ Commitment to wage $W_{T}$ is a convenient assumption. It prevents having to worry about ex post bargaining between firm and retained workers and avoids issues about the initial firm to deviate from $W_{\mathrm{T}}$ to offer some subgroup of workers less than that. Other authors have explored the implications of ex post negotiation for wage setting, see in particular, Stole and Zwiebel (1994). 
Proposition 1: The equilibrium starting wage for risky workers is higher than the equilibrium starting wage for safe workers. This premium reflects the option value of hiring a risky worker.

Proof:

Competitive equilibrium requires that expected output equal expected wage over the lifetime. If $\mathrm{r}$ is the interest rate, then

$$
\int_{0}^{\tau}\left(\bar{M}-W_{1}\right) e^{-r t} d t+P_{R} \int_{\tau}^{T}\left[E\left(M+S_{1} \mid M+S_{1}>W_{T}\right)-W_{T}\right] e^{-r t} d t=0
$$

where $P_{R}$ is the probability of being retained, i.e., $\operatorname{prob}\left(\mathrm{M}+\mathrm{S}_{1}>\mathrm{W}_{\mathrm{T}}\right)$. This can be rewritten as

$$
W_{1}=\bar{M}+\frac{e^{-\pi}-e^{-r T}}{1-e^{-\pi}} P_{R}\left[E\left(M+S_{1} \mid M+S_{1}>W_{T}\right)-W_{T}\right]
$$

The second term on the r.h.s. of (4) is positive, which implies $W_{1}>\bar{M}$. Since riskless hires receive ${ }^{\bar{M}}$, the starting wage for risky workers exceeds that for safe workers. III

Because risky workers have option value, a firm is willing to pay a higher wage to workers for whom there is significant upside. Workers who do not work out can always be let go, which means that for risky workers, the ex post distribution of output is higher than the ex ante distribution of output. Safe workers lack the upside and downside. But the value 
of the upside exceeds the cost of the downside because losses can be truncated. It is this asymmetry that raises the initial price of risky workers.

Firing Costs:

The previous analysis assumed implicitly that a worker could be terminated without cost. But in some situations and countries, there are real costs associated with laying off workers. Does this reverse the conclusion that it pays to hire a risky worker over a safe one at any given wage? The answer is no. The logic is straightforward. At worst, the firm can simply keep all workers. In this case, the risky worker has expected value $\bar{M}$, which is identical to the value of the safe worker. As long as the ability to lay off poorly suited workers has some positive value, the expected value of the risky worker at time of hire exceeds that of the safe worker.

Formally,

Proposition 2: The existence of firing costs can at worst make a firm indifferent between hiring a risky worker and a safe worker at the same wage. Under most circumstances, the risky worker is preferred.

Proof:

The proof is immediate. At worst, the firm can retain every worker that it hires, receiving $\bar{M}$ of expected output. If the firm fires some workers, the value of doing so must be positive after taking into account firing costs. Since the safe worker is worth ${ }^{\bar{M}}$, the risky worker is no less valuable than the safe one. III

"Actually, the worker "quits" voluntarily because the firm is unwilling to offer a wage that beats the one offered by another firm. 
Related to proposition 2 is that the time horizon matters, as does the length of time that it takes to determine the worker's output. The longer is the worklife, the greater is the value of the risky worker. Thus,

Proposition 3: The premium that the newly hired risky worker receives over the safe worker increases in the length of the worklife. Furthermore, the premium decreases as the duration of the probation period increases.

Proof: The wage that newly hired risky workers receive is

$$
W_{1}=\bar{M}+\frac{e^{-r}-e^{-r T}}{1-e^{-\pi}} P_{R}\left[E\left(M+S_{1} \mid M+S_{1}>W_{T}\right)-W_{T}\right]
$$

as defined in (4) above. Eq. (2), which defines $W_{T}$ reveals that $W_{T}$ is independent of $T$ and t. Since neither $M$ nor $S_{1}$ depend on $T$ or $\tau, P_{R}$ is independent of $T$ and $\tau$. Therefore,

$$
\frac{\partial W_{1}}{\partial T}=\frac{r e^{-r T}}{1-e^{-r T}} P_{R}\left[E\left(M+S_{1} \mid M+S_{1}>W_{T}\right)-W_{T}\right]
$$

and 


$$
\frac{\partial W_{1}}{\partial \tau}=\frac{-r e^{-r T}}{1-e^{-r \tau}}\left[1+\frac{e^{-r \tau}-e^{-r T}}{1-e^{-r \tau}}\right] P_{R}\left[E\left(M+S_{1} \mid M+S_{1}>W_{T}\right)-W_{T}\right]
$$

which are positive and negative, respectively. III

The intuition is clear. The value of the upside increases as the amount of time to recoup the returns increases. As a result, the equilibrium wage that a risky hire receives increase as the amount of post-probation work time increases. Post probation work time increases as $\mathrm{T}$ rises and as $\tau$ falls. At the extreme, were $\tau=\mathrm{T}$, then the firm would not learn the worker's productivity until the retirement date, at which point it would be too late to use the information. Under these circumstances the option value would be zero and (4) shows that $\mathrm{W}_{1}$ would equal $\bar{M}$.

Old v. Young:

This analysis provides two rationales for hiring young over old workers. First, the variance of the estimate of a younger worker's productivity is likely to be higher than that of an older workers. Thus, for two workers with the same expected output, the upside (and downside) are larger for younger workers. Proposition 1 implies that young workers, for whom precision of the estimate is low, are better buys than old workers at a given wage.

Second, $\mathrm{T}$ is larger for young workers. Even if variance were the same, the remaining worklife is longer for young workers, raising the option value. Proposition 2 implies that at the same wage, young workers are better buys than old workers because they have a longer post-probation duration of service. 
Firms are willing to pay a premium for young workers because of their higher option value. Indeed, at the same wage, a firm prefers a younger worker even to an older worker with somewhat higher expected quality. The younger worker deficit in expected quality that the firm is willing to tolerate increases as the amount of uncertainty about younger worker quality rises. Eq. (4) reveals that expected output of a young worker exceeds $\bar{M}$ by

$$
\frac{e^{-r t}-e^{-r T}}{1-e^{-r \tau}} \quad P_{R}\left[E\left(M+S_{1} \mid M+S_{1}>W_{T}\right)-W_{T}\right]
$$

so a younger worker who is paid $W_{1}$ would be preferred to an older worker who is paid exactly his output as long as the older worker's output exceeds the younger worker's output by less than ${ }^{9}$

$$
\frac{e^{-r \tau}-e^{-r T}}{1-e^{-r \tau}} \quad P_{R}\left[E\left(M+S_{1} \mid M+S_{1}>W_{T}\right)-W_{T}\right]
$$

The Individual Firm's Hiring Choice:

${ }^{8}$ In actuality, the expected value of an older worker's output is less than that of a younger worker. When a new firm hires an older worker, it does so at wage $W_{T}$. The worker's quality is not known with certainty, but it is more certain than that for the younger worker. The distribution of older worker's quality in the new firm is given by

$$
M+S_{j} \mid M+S_{1}<W_{j}
$$

If $S_{j}$ and $S_{1}$ are i.i.d, then the distribution of output for older workers is tighter than that for younger workers since it results from truncation of the initial distribution. The expected value of the older workers is equal to

$$
E\left(M \mid M+S_{1}<W_{j}\right) \text {, }
$$

which is necessarily less than $E(M)$. 
Market equilibrium guarantees that the marginal firm is indifferent between hiring the risky worker at $\mathrm{W}_{1}$ and the safe worker at $\bar{M}$. But inframarginal firms have an unambiguous preference for either the risky worker or safe worker. The last section provides some guidance on which type of worker a firm will choose.

Consider a firm in a declining industry that expects to be out of business before $\tau$ periods have elapsed. The risky worker produces no option value for this firm. Since his expected value is $\bar{M}$, the firm in a declining industry would be indifferent between the risky worker and safe worker at the same wage. But $\mathrm{W}_{1}$ exceeds $\bar{M}$. Thus, firms in declining industries should prefer older workers with short work horizons and well-established track records. Conversely, firms that expect to have long horizons prefer risky workers at starting wage $W_{1}$. Silicon Valley is known as a place where workers are young and turnover rates are high. This is consistent with the prediction. Conversely, the Rust Belt should be disproportionately represented by older workers who leave only to exit from the labor market.

Male v. Female:

It is possible to rationalize higher demand for male workers than for female workers by appealing to variance. It is well-known that IQ tests, which are normalized to produce the same mean scores for males and females, produce higher variance for males than for females. ${ }^{10}$ The arguments against using IQ as the appropriate measure of ability are well-

\footnotetext{
${ }^{10}$ It is conceivable, of course, that the exam questions could be selected so that normalization of the second and higher moments, as well as the mean, are achieved. But this is rarely done. The result of ignoring higher moments is that variance is larger for males.
} 
known. Still, as a predictor of labor market success, IQ is relevant ${ }^{11}$ and there is no doubt that outcomes are more diverse for males than females. Virtually all the very high earning executives are male. At the other end, large negative deviations are dominated by males who disproportionately occupy prisons, mental institutions, and form the bulk of individuals who live on the street. Results in the education literature reveal the higher variance in test scores among males. Han and Hoover (1994) report that average differences in achievement between males and females were relatively small, but that male performance was generally more variable than that of females. Specifically, males at average and below-average abilities have markedly lower achievement than females. Doolittle and Welch (1989) present results on ACT administered Collegiate Assessment of Academic Proficiency achievement tests. This is a selected sample because it looks only at those who were in college. Even here, the variance on all three components - reading, writing and mathematics - were higher for males.

If males are risky and females are safe, employers would prefer to hire males at the same wage. Just as young workers have option value, males would have more option value than females. This would also imply that there is more sorting among newly hired males. It does not imply that turnover rates are higher for males since the kind of turnover of interest for this model is that which occurs at the end of probation, which probably occurs early in a worker's career. It is quite possible that females have higher turnover rates, but that the patterns resemble those shown in fig. 2 . Some evidence on turnover rates is provide by Gronau (1988), whose results are not inconsistent with this view.

More direct evidence is furnished by Higuchi (1994). Higuchi reports on turnover

\footnotetext{
${ }^{13}$ The National Longitudinal Surveys report scores on the Armed Forces Qualifying Test (AFQT), an achievement/IQ test given to all inductees and given to individuals in the NLS samples. Virtually all researchers who have used these variables find that they enter significantly into wage regressions. Recent use of this variable has been made by Farber and Gibbons (1994) and by Altonji and Pierret (1996).
} 
experiences in both the U.S. and Japan. For the U.S., data from the 1977 CPS reveal that for individuals 18-24 years old, males actually have higher turnover rates than females. The pattern is reversed in all subsequent categories. For Japan, data from the Employment Structure Survey are used to compare male/female turnover rates in 1977 and 1987. Although female turnover rates are always higher than male turnover rates in Japan, the two rates are closest for the youngest workers. For example, in 1987, the turnover rate for males 18-24 years old was $19.5 \%$ and for females it was $23.4 \%$. By the time workers are 25-34 years old the female turnover rate rises to almost three times the male rate, but drops back to a ratio of two-to-one after the childbearing years.

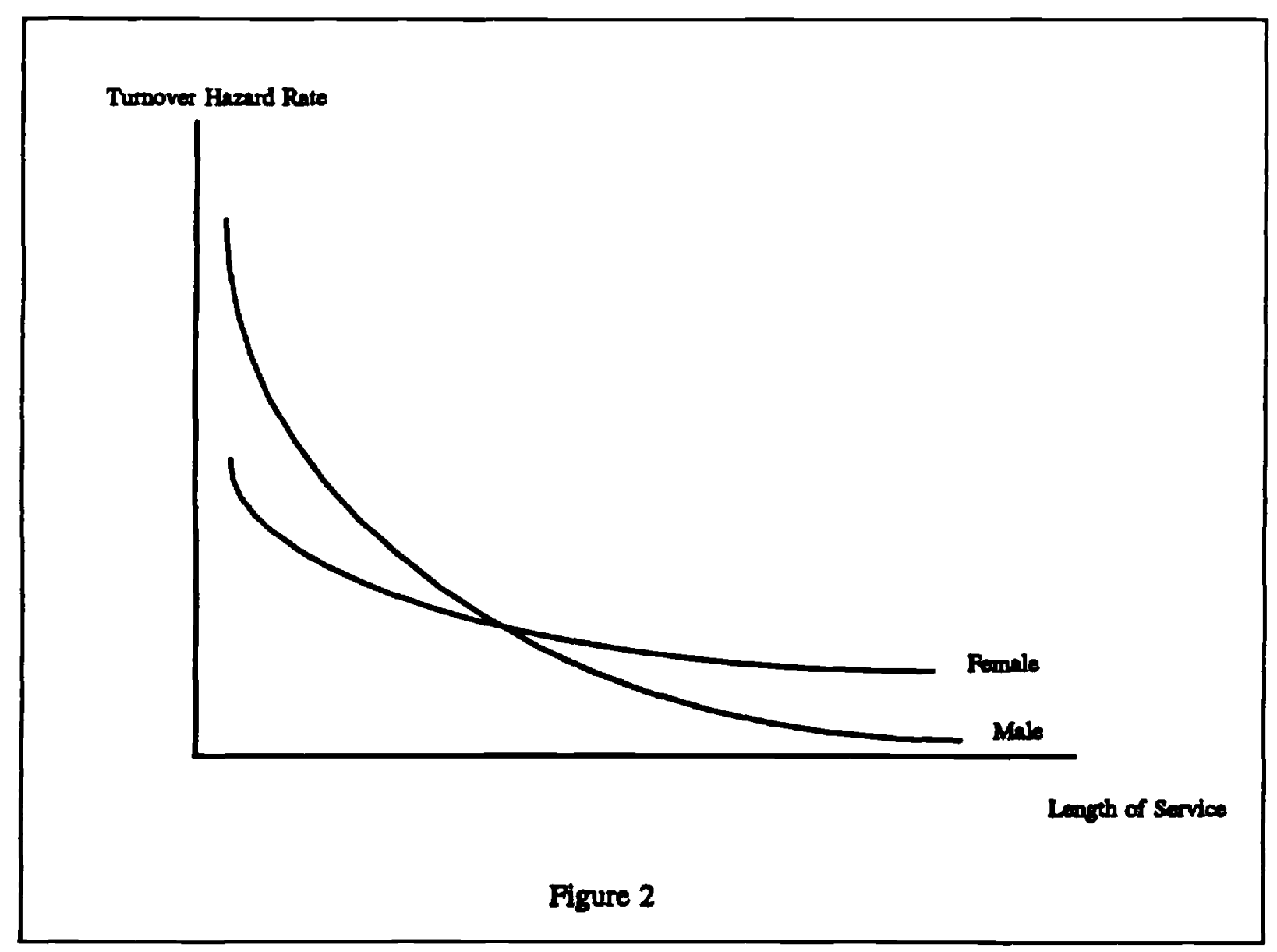


The Value of Information:

While variance is desirable, a firm would not willingly throw away information on a given employee. On the contrary, a firm would be willing to pay something to have specific information on a given employee even though the information will increase the precision of the estimate and reduce the ex post option value. By obtaining ex ante information, the firm is able to truncate the lower tail of the distribution of hired workers. The firm thereby

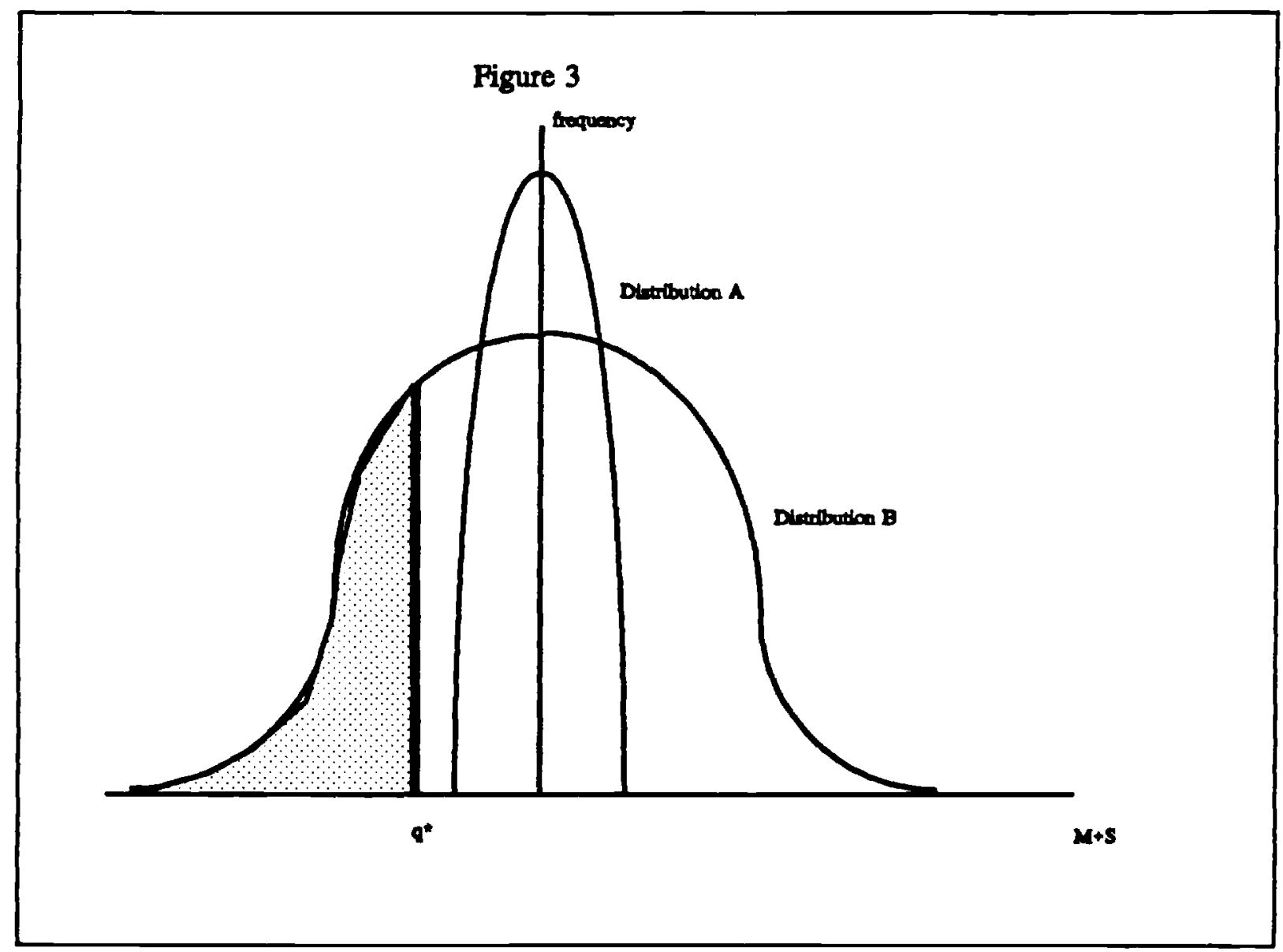

raises the mean of those workers that it hires in period 1. This is shown in figure 3 .

The high variance distribution is distribution $B$. When the firm buys information, it does not simply reduce the variance, it also truncates the distribution and raises the mean. 
The shaded area below the cutoff point, $q^{*}$, is eliminated. The firm is not trading distribution $B$ for distribution $\mathbf{A}$. In the discussion above, the experiment imagined was a choice between distribution $\mathrm{A}$ and the untruncated distibution $\mathrm{B}$. When a firm buys information, it does not cutoff the top of the distribution. It retains the high valued workers, but is able to eliminate the bottom of the distribution. It is for this reason that firms devote resources to screening workers.

The equilibrium market wages, $W_{1}$ and $W_{T}$ are set such that the expected net value of hiring a risky worker is exactly zero. But if instead, the firm knew the exact value of the worker, its hiring decision would be altered. It would never pay to hire any worker whose value of $M+S_{1}$ fell below ${ }^{12}$ the cutoff level

$$
M+S_{1}>\frac{W_{1}\left(1-e^{r T}\right)+W_{T}\left(e^{-r T}-e^{-r T}\right)}{1-2 e^{-r T}+e^{-r T}}
$$

Obtaining information not only reduces variance, it raises expected value relative to wage. First note that a the firm must pay a $W_{1}$ to a worker about whom the market has only

\footnotetext{
${ }^{12}$ A firm must do better by hiring the worker than not so required is that

$$
\left(M+S_{1}-W_{1}\right)\left(\frac{1-e^{-r T}}{r}\right)+\left(M+S_{1}-W_{7}\right)\left(\frac{e^{-r T}-e^{-r T}}{r}\right)>0
$$
}

or

$$
M+S_{1}>\frac{W_{1}\left(1-e^{r T}\right)+W_{T}\left(e^{-r}-e^{-r T}\right)}{1-2 e^{-r T}+e^{-r T}}
$$


imperfect information. Even if the firm knew that the worker's value were less than $\bar{M}$, any attempt to pay less than $W_{1}$ would not be accepted by the worker who could get $W_{1}$ at an ignorant firm. But there are groups of workers on whom the firm loses when they are hired at an initial wage of $W_{1}$. Consider, for example, all workers whose value of $M+S_{1}<W_{1}$. The firm loses money on these workers and on all whose output falls below the previously given cutoff value.

The firm would rather hire risky workers than safe workers with the same wage and expected output because the firm can take advantage of the upside and truncate the downside. But the firm can do even better if it can truncate the downside before hiring. Then it need not pay wages that exceed output during the probation period on workers who will be terminated after probation. This information is valuable and rationalizes the expenditures that firms make screening applicants at the time of hire.

Private Information or Turnover Costs are Necessary for Risky Workers to Have Option Value:

Were information public, the initial employer would have no advantage over any other firm. As such, paying $\mathrm{W}_{1}>\bar{M}$ would not be feasible. At time $\tau$, when ability is revealed, firm 1 would be willing to pay up to $M+S_{1}$ and any other firm $j$ would be willing to pay up to $M+S_{j}$. In a market with $N$ firms, the initial employer would keep the worker only $1 / N$ of the time because the firm keeps the worker only when $S_{1}$ exceeds $S_{j}$ for all $j \neq 1$. The rent received would be 


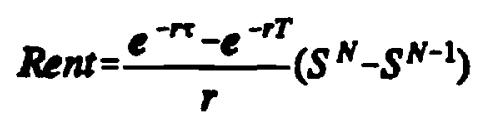

where $S^{h}$ is the $h^{\text {th }}$ order statistic on the random variable $S$, which, recall, is i.i.d. . This follows because the firm receives $M+S_{1}$ and but pays the next highest value of output. The expected difference is $S^{N}-S^{N-1}$, because the initial firm only keeps the worker when it draws the highest value of the firm specific component. Thus, the expected rent to the firm that makes the initial hire is

$$
\text { Expected Rent }=\frac{e^{-r T}-e^{-r T}}{N r}\left(S^{N}-S^{N-1}\right)
$$

The initial employer has no advantage. Every firm receives that same expected rent after productivity is revealed, whether the firm was the initial employer or not. Competition guarantees that the initial employer pay a wage equal to $\bar{M}$ during the first $\tau$ periods because this is the expected value. After that, the worker is equally likely to end up at any given firm. Thus, there is no option value to hiring the risky worker.

Suppose, however, that a worker has to bear some moving costs to switch from the initial firm to another. Then the initial employer would have and advantage. If moving costs are denoted $k$, then the initial firm retains the worker whenever 
$S_{i}+k \underset{j}{\operatorname{Max}} S_{j} \quad j \neq i$

The probability of retention rises above $1 / \mathrm{N}$ and the expected rent rises as well, since the firm can pay anything over $\max _{j} S_{j}-k \quad(j \neq i)$ to retain the worker. This discussion leads to the following proposition:

Proposition 4: In order for there to be option value to hiring risky workers, the initial employer must have an advantage over other firms. Two types of advantages are private information of a worker's ability and mobility costs that make a worker prefer his current firm over other firms.

Sources of Risk:

The model has two sources of risk. General output, $M$, is treated as a random variable, as is specific output, S. It is only variations in specific output that provides option value. To see this, suppose that $\mathrm{S}$ were invariant across firms. Without loss of generality, assume that $S=0$. Then there is no reason for workers to be let go. Any worker who is retained by the initial employer has exactly the same value at any other firm. Outsiders will match any offer that the initial employer makes because any wage that is profitable for the initial firm is also profitable for any other firm. Thus, the initial employer cannot capture any returns on general risk. If information remains private, an equilibrium is simply to pay each worker $\bar{M}$ throughout his career. Put differently, if $\mathrm{S}=0$, then there is no solution to (2). There is no wage that keep the good workers, with lower quality workers moving to other firms. Thus, for risk to have some option value, the risk must be firm specific. 
Indeed, it is totally unnecessary that $M$ be risky. If $S$ is non-degenerate and different across firms, risky workers have option value even when $\mathrm{M}=\bar{M}$ for all workers. Risk is only firm specific, but all propositions hold. Under these conditions, the solution to (2) is $\mathrm{W}_{\mathrm{T}}=\bar{M}$. Every worker who is laid off is worth an expected value of $\bar{M}$ to an outside firm because $E\left(S_{j}\right)=0$. This is a well-defined equilibrium.

The conclusion is firm specific risk, not variations in general ability, is necessary to create option value.

\section{Conclusion}

Firms faced with the choice of hiring a worker with a well established track record or one about whom little is known prefer the uncertain one at the same wage. This preference by firms results in a market equilibrium where new workers with uncertain quality command a premium. Firms that have long time horizons and are most likely to take advantage of the option value are willing to pay the higher price and employ risky workers. Firms with short horizons employ safe workers.

Young workers are riskier than older workers and male workers may be riskier than female workers. This implies a preference for young males at a given market wage. Put differently, the market will adjust the wages of the young and of males so that for a given expected quality young workers and male workers earn more. This also implies higher turnover rates among the young male workers than among young females. There is some support in the literature for this implication.

Despite the value of variance, information has value. By obtaining information ex 
ante, a firm can make a better hiring decision and restrict hires to those who exceed a welldefined cutoff level.

Finally, risky workers have no option value unless the initial employer has some advantage over other firms in the market. Private information about a worker's output or worker mobility costs may provide that advantage. Furthermore, it is risk in the firm specific component of output that provides option value. Even unknown variations in general ability provide no option value to the initial hirer. 


\section{References}

Altonji, Joseph and Charles Pierret. "Employer Learning and Statistical Discrimination," Northwestern University, (draft July 1995 for Lake Biwako Conference). Forthcoming, this volume, 1996.

Doolittle, A. and C. Welch "Gender Differences in Performance on a College-Level Achievement Test," ACT Research Report Series, 1989-9.

Farber, Henry and Robert Gibbons. "Learning and Wage Dynamics." Working Paper \#328. Industrial Relations Section, Princeton University, May 1994.

Gibbons, Robert and Lawrence Katz. "Layoffs and Lemons." Journal of Labor Economics, 9,4 (Oct. 1991), pp. 351-380.

Gittins, J. and D. Jones "Adynamic Allocation Index for the Sequential Allocation of Experiments," in Progress in Statistics, J. Gani, et. al., eds. Amsterdam: North Holland, 241-66.

Greenwald, Bruce C. "Adverse Selection in the Labor Market," Review of Economic Studies 53 (July 1986): 325-47.

Gronau, Reuben "Sex-related Wage Differentials and Women's Interrupted Labor Careers The Chicken or the Egg," J. of Lab. Econ., 6,3, July 1988, pp. 277-301.

Han, Lei and H.D. Hoover. "Gender Differences in Achievement Test Scores," paper presented at the Annual Meeting of the National Council on Measurement in Education (New Orleans, La., April 5-7, 1994).

Higuchi, Yoshio "Effects of Job Training and Productivity Growth on Retention of Male and Female Workers in Japan," in Labor Markets and Economic Performance Europe, Japan and the USA, ed. by Toshiaki Tachibanaki. : St. Martin's Press, 1994, pp. 155-182.

Lazear, Edward P. "Raids and Offer-Matching," in Ehrenberg, Ronald, ed. Research in Labor Economics, Vol. 8, 1986, part A, pp. 141-65.

Reinganum, Jennifer "Nash Equilibrium Search for the Best Alternative," J. Econ. Theory, $30,139-52$ (1983).

Rothschild, Michael. " " A Two-Armed Bandit Theory of Market Pricing," J. Econ. Theory, 9, 185-202.

Stole, Lars and Jeffrey Zwiebel. "Intrafirm Bargaining under Nonbinding Contracts," Stanford University GSB Working Paper, 1994.

Waldman, Michael. "Job Assignments, Signalling, and Efficiency," Rand Journal of Economics 15 (Summer 1984): 255-67. 
Weitzman, Martin. "Optimal Search for the Best Alternative," Econometrica, 47,3, (May 1979), 641-54. 